\title{
PREPARATION AND EVALUATION OF THEOPHYLLINE LOADED BOVINE SERUM ALBUMIN MICROSPHERES
}

\author{
K. I. Saleh, M. A. Ibrahim and T. M. Faris
}

Department of Pharmaceutics and Industrial Pharmacy, Faculty of Pharmacy, Al-Azhar University at Assiut, Assiut, Egypt

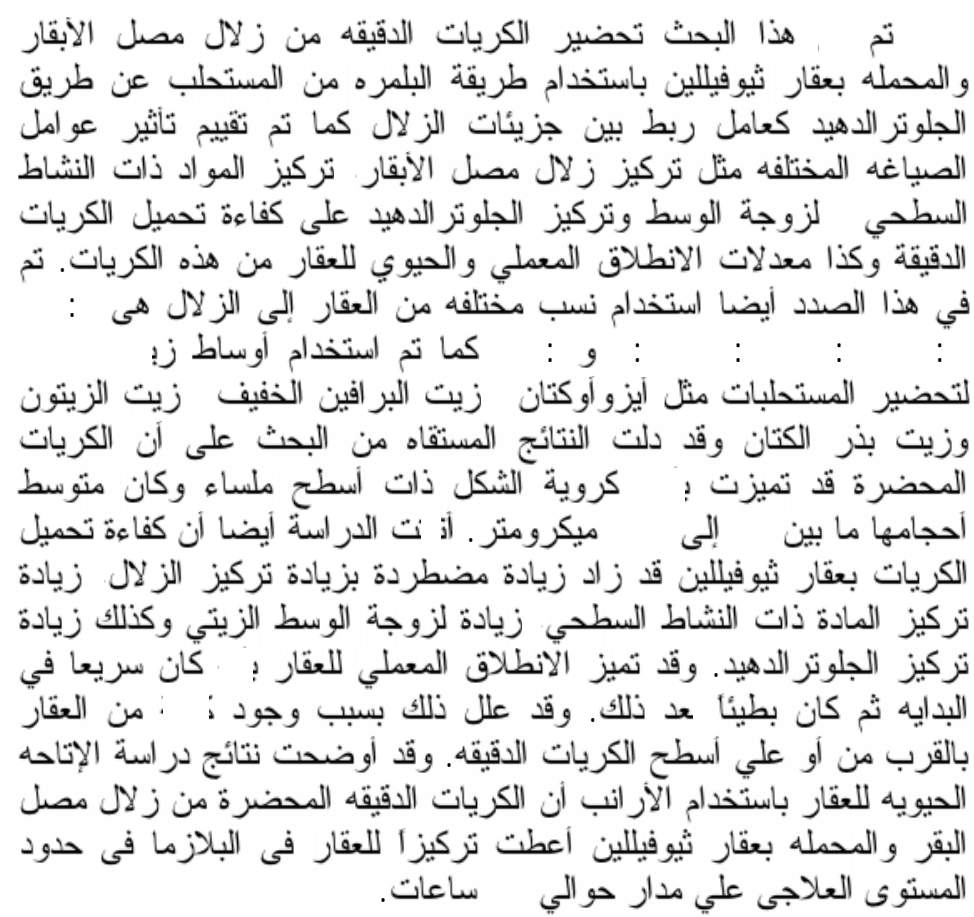

Theophylline-loaded bovine serum albumin (BSA) microspheres were prepared by an emulsion polymerization method using glutaraldehyde as the crosslinking agent. The study was designed to evaluate the effects of different formulation parameters as BSA concentration, surfactant concentration, hydrophilic lipophilic balance $(H L B)$, dispersion medium viscosity and glutaraldehyde concentration on the extent of drug loading, size of microsphere and the in-vitro as well as the in-vivo release rates of theophylline from such microspheres. Drug polymer ratios of $1: 1,1: 2,1: 3,1: 4$, 
1:5 and 1:6 were investigated. Span 80 was used as a surfactant at different concentrations. Moreover, Different span $80 /$ tween 80 blend concentrations; $0.5,1.0$ and $2.0 \% \mathrm{w} / \mathrm{v}$ were used to study the effect of HLB. Also different dispersion media; isooctane, light paraffin oil, olive oil and Linseed oil were used for microspheres preparation. In addition, different glutaraldehyde concentrations; 5,10 and $25 \% v / v$ were used. It was found that all micro-spheres were spherical with the mean particle size of 90-180 $\mu \mathrm{m}$. The results revealed also that: as the concentration of BSA increases, the drug loading is increased. Increasing surfactant concentration and viscosity of the dispersion medium has led to decrease the particle size, while increasing glutaraldehyde concentration nearly had no effect. Furthermore, encapsulation efficiency was found to be directly proprortional to albumin content, surfactant concentration, viscosity of the dispersion medium and glutaraldehyde concentration. Drug release from the prepared microspheres displayed a biphasic pattern characterized by an initial burst, followed by a slower release period, which may be attributed to the presence of theophylline material near to or onto the microspheres surfaces. The bioavailability of theophylline from the prepared microspheres was evaluated in rabbits. The prepared microspheres were found to control theophylline release even up to 10 hrs. The peak serum concentrations of such microspheres were within the therapeutic level. The results indicate also that the previoiusly mentioned formulation parameters have a prnounced impact to control the release of the entrapped drug.

\section{INTRODUCTION}

Albumin microspheres have attracted considerable attention for several years as a matrix for controlled and sustained delivery of many drugs. These protein microspheres provide a potentially useful vehicle for drug delivery to endocytic cells since they are physically and chemically stable, rapidly removed from the vascular system by phagocytosis, amenable to large-scale preparation, readily metabolized and capable of accommodating a broad variety of the drug molecules in a relatively nonspecific fashion ${ }^{1-12}$.

Glutaraldehyde cross-linked albu$\mathrm{min}$ is relatively non- immunogenic in nature, and studies have shown that albumin micro-spheres are biodegradable in the muscle in about two months without causing any adverse tissue reactions ${ }^{13}$. Suspension crosslinking of albumin can be accomplished either by direct reaction between functional groups on the 
polypeptide side chains (selfcrosslinking), or by the use of the crosslinking agents. Drug release from albumin microspheres can take place via various routes, such as total microsphere disintegration, microsphere hydration, surface erosion, particle diffusion and leaching ${ }^{14}$. Most of the in-vitro studies on the release of drugs incorporated into microspheres focused on biphasic profile describes an initial fast release (burst effect) followed by a slower first order release profile ${ }^{15-19}$. In this study, we have investigated the effect of five process factors, drug: polymer ratio, surfactant (span 80, HLB 4.3) concentration, blend of surfactants ( $\operatorname{span} 80$ / tween 80, HLB 5) concentration, dispersion medium viscosity and glutaraldehyde concentration on theophylline loaded albumin microspheres characteriza-tion and on the in-vitro release profiles of theophylline. This study also reports the bioavailability of theophylline from the prepared microspheres in rabbits.

\section{MATERIALS AND METHODS}

\section{Materials}

- Bovine serum albumin (BSA), glutaraldehyde $25 \%$, and diethyl ether were purchased from Fluka Chemie GmbH, Germany.

- Anhydrous Theophylline was purchased from Sigma Chemie GmbH, Germany.

- All other ingredients and chemicals used were of reagent grade.
- Rabbits weighing 1.75-2.25 kg were used in the bioavailability studies.

\section{Equipment}

- Spectrophotometer

UV.1601

(Shimadzu Co., Japan).

- Sieve Shaker, Rx-86-1 (ColeParmer Instrument Co., USA).

- Dissolution test apparatus, SR11 6 Flask (Hanson Co., USA).

- Electrical digital balance (Precisa XB 220, Swisserland).

- Over head stirrer (Heidolph, Germany).

- Centrifuge (Cole-Parmer 8890, USA).

Methodology

Preparation of BSA microspheres

BSA microspheres were prepared using emulsion polymerization technique slightly modified as described by Tomlinson et al. $^{20}$. About $500 \mathrm{mg}$ of BSA powder were dissolved in $1 \mathrm{ml}$ phosphate buffer. The solution of BSA was dropped to $100 \mathrm{ml}$ light paraffin oil during stirring at $500 \mathrm{rpm}$. The microspheres were stabilized by dropping about 0.6 $\mathrm{ml}$ of a $25 \%(\mathrm{v} / \mathrm{v})$ glutaraldehyde with continual stirring for $60 \mathrm{~min}$. to ensure microspheres formation. After stabilization of the microspheres, 80 $\mathrm{ml}$ of anhydrous diethyl ether was added and stirring was continued for another $5 \mathrm{~min}$. then set aside and the supernatant layer was decanted. Complete removal of residual oil was achieved by washing the albumin 
microspheres in anhydrous diethyl ether $(100 \mathrm{ml})$ three times followed by washing once with petroleum ether (100 ml).

Theophylline loaded BSA microspheres were prepared using the same previous preparation method except that theophylline powder (100 $\mathrm{mg}$ ) was dispersed in the BSA solution where theophylline has a low aqueous solubility ( $1 \mathrm{~g}$ in about 120 $\mathrm{ml})$. In this study we followed the experimental design which studies the effect of each process factor individually through different levels. The level at which the drug is highly entrapped was chosen and established during studying the second process factor and vice versa. To study the effect of drug: polymer ratio, different ratios were selected $(1: 1,1: 2,1: 3$, 1:4, 1:5 and 1:6). To study the effect of the surfactant concentration, different span 80 (has HLB value of 4.3) concentrations were selected; $0.5,1$ and $2 \% \mathrm{w} / \mathrm{v}$. To study the effect of achieving a surfactant of HLB value of 5 (which is essential for proper emulsification when mineral oil or vegetable oil is used as a dispersion medium $)^{21}$, different span $80 /$ tween 80 blend concentrations were selected; $0.5,1$ and $2 \% \mathrm{w} / \mathrm{v}$. To obtain a blend of HLB 5, span 80 (HLB 4.3) and tween 80 (HLB 15) were used in the percentage ratio of 93.46: 6.54, respectively. Also different batches were prepared using different dispersion media; isooctane, light paraffin oil, olive oil and Linseed oil as well as different glutaraldehyde concentrations; 5,10 and $25 \%$ v/v were used.

\section{Characterization of microspheres \\ Particle size distribution of the prepared BSA microspheres}

Determination of microspheres particle size was performed through sieving the yield of the prepared microspheres using a set of sieves (40 $\mu \mathrm{m}-515 \mu \mathrm{m})$ and specifying the weight of the fractions that passed through each sieve. The particle size distribution curve was constructed through plotting percentage of weight fraction against microsphere particle $\operatorname{size}^{13}$.

\section{Drug encapsulation efficiency}

An amount of $10 \mathrm{mg}$ of theophylline microspheres was weighed accurately. The amount of drug loaded was determined by digesting the amount of microspheres in $5 \mathrm{ml}$ of glacial acetic acid for 24 hrs $\left(4^{\circ} \mathrm{C}\right)$ followed by centrifugation (5000 rpm) to completely separate the precipitated mass. The amount of theophylline in the supernatant of each sample was determined by measuring the absorbance in the spectrophotometer at $271.5 \mathrm{~nm}$. Corrections for albumin contribution to absorbance were made using reference solutions of placebo microspheres also in glacial acetic acid.

\section{In-vitro drug release from albumin microspheres \\ In-vitro release of theophylline} from BSA microspheres was carried 
out using the USP XXII paddle method. The dissolution media were $900 \mathrm{ml}$ of simulated gastric fluid (SGF) and simulated intestinal fluid (SIF) maintained at $37 \pm 0.5^{\circ} \mathrm{C}$. The paddles were positioned $2.5 \mathrm{~cm}$ from the bottom of the vessel and rotated at speed of $100 \mathrm{rpm}$. Ten $\mathrm{mg}$ of the prepared microspheres was transferred to the stirred dissolution medium in each vessel. At a predetermined time intervals, samples were withdrawn by pipette fitted with a filter and measured spectrophotometerically at $271.5 \mathrm{~nm}$ for determining drug concentration. Blanks were used.

\section{Kinetics of the in-vitro drug release}

The data obtained from the experiments were analyzed by means of computer, using linear regression analysis to specify the mechanism of drug release. The correlation coefficient obtained after applying the zero order, the first order and Higuchi's diffusion model were compared. The model which showed the highest correlation coefficient is assigned as the mechanism of release.

\section{Theophylline bioavailability studies}

Rabbits weighing 1.75-2.25 kg were used for this study. Each rabbit was given a dose of $15 \mathrm{mg} / \mathrm{kg}$ body weight of theophylline powder or an equivalent dose in microspheres form with $10 \mathrm{ml}$ water orally through a catheter. In intravenous administration, a dose of $19.04 \mathrm{mg}$ of aminophylline injection USP (25 $\mathrm{mg} / \mathrm{ml}$ ), equivalent to $15 \mathrm{mg}$ of theophylline $/ \mathrm{kg}$, was administered through a catheter into the marginal ear vein of the rabbit over 5 minutes. Venous blood samples $(1 \mathrm{ml}$ each $)$ were collected at 1, 2, 4, 6, 8, 12, 18 and $24 \mathrm{hrs}$ from the Jugular vein after administration. Samples were incubated at $37^{\circ} \mathrm{C}$ till clotted then centrifuged at $2500 \mathrm{rpm}$ for $10 \mathrm{~min}$ and the serum was separated. Theophylline in the serum was extracted and analyzed in the following way; $0.4 \mathrm{~g}$ of ammonium sulphate were added to $0.5 \mathrm{ml}$ of serum and theophylline was extracted using $15 \mathrm{ml}$ of chloroform/hexane (7:3 mixture) by stirring the contents using magnetic stirrer for $40 \mathrm{~min}$. The organic layer was separated and $10 \mathrm{ml}$ of which were extracted using $3 \mathrm{ml}$ of $0.1 \mathrm{M}$ carbonate buffer ( $\mathrm{pH} 9.0)$ after shaking for $30 \mathrm{~min}$. The aqueous layer was then separated. The absorbance of this layer was measured at $271.5 \mathrm{~nm}^{22}$.

The results of the bioavailability studies were used to determine the pharmacokinetic parameters. The elimination rate constant $\mathrm{K}_{\mathrm{el}}$ was determined from the slope of the terminal linear portion of the semilogarithmic curve when serum concentration was plotted against time using linear regression analysis as reported by Maruyama $e l \mathrm{al}^{23}$. Also the elimination half-life values were determined by dividing 0.693 by the elimination rate constant $\mathrm{K}_{\mathrm{el}}$. The area under the concentration-time curve AUC is calculated from the following equation:

$$
\mathrm{AUC}_{0-\infty}=\mathrm{AUC}_{0-\mathrm{t}}+\mathrm{C}_{\mathrm{t}} / \mathrm{k}_{\mathrm{el}}
$$


where AUC ${ }_{0-t}$ is the area under the curve from time 0 to $t$ calculated using trapezoidal rule and $\mathrm{C}_{\mathrm{t}}$ is the concentration at time $t$.

All the other pharmacokinetic parameters for in-vivo study of theophylline are calculated and tabulated.

\section{RESULTS AND DISCUSSION}

\section{Particle size analysis}

It was found that the drug: polymer ratio of 1:1 did not form microspheres. Increasing the polymer content has shown to increase the size of the microspheres. The results (Fig. 1) reveal that by decreasing the drug concentration via decreasing the drug: polymer ratio from 1:2 to $1: 6$ (i.e, increasing the polymer content), the amount of the microspheres having particle size more than 130 $\mu \mathrm{m}$ was increased from $20 \%$ to $74 \%$.

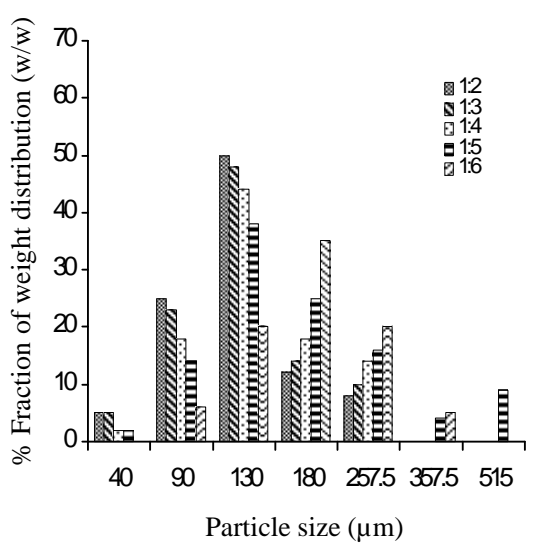

Fig. 1: Effect of different drug: polymer ratios on the \% fraction of weight distribution of theophylline loaded BSA microspheres.
It was noticed that increasing span 80 concentration led to decrease in particle size ${ }^{24}$. The results reveal that upon increasing span 80 concentration from $0 \%$ to $0.5,1$ and $2 \%$, the amount of the microspheres having particle size less than $130 \mu \mathrm{m}$ was increased from 54 to 84, 91 and $92 \%$, respectively (Fig. 2).

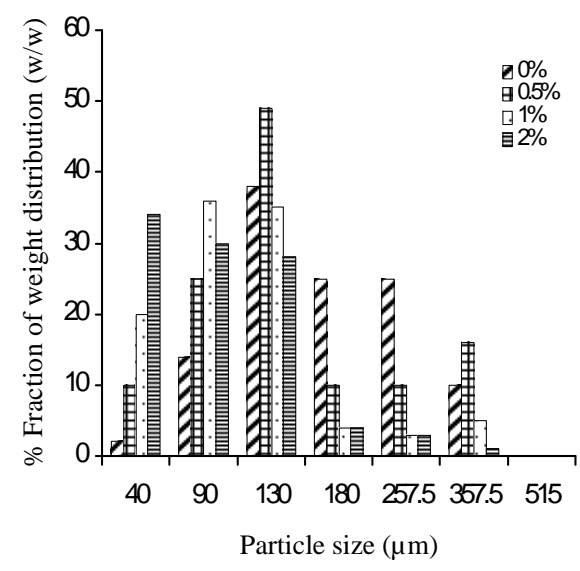

Fig. 2: Effect of different span 80 concentrations $(\% \mathrm{w} / \mathrm{v})$ on the $\%$ fraction of weight distribution of theophylline loaded BSA microspheres prepared using drug: polymer ratio of $1: 5$.

Figure 3 shows that there is a slight increase in the amount of the microspheres having particle size less than $130 \mu \mathrm{m}$ (from 82 to $97 \%$ ) upon increasing span $80 /$ tween 80 blend concentration from 0.5 to $1 \% \mathrm{w} / \mathrm{v}$. By increasing the blend concentration from 1 to $2 \% \mathrm{w} / \mathrm{v}$, there was no change in the amount of the microspheres having particle size less than $130 \mu \mathrm{m}$ but there was an increase in the amount of the microspheres having particle size less than $40 \mu \mathrm{m}$ from $29 \%$ to $41 \%$, respectively. 


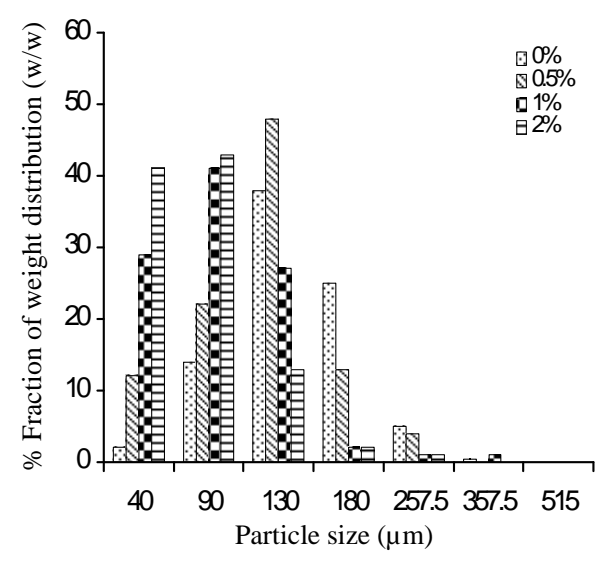

Fig. 3: Effect of different span $80 /$ tween 80 blend concentra-tions $(\% \mathrm{w} / \mathrm{v})$ on the $\%$ fraction of weight distribution of theophylline loaded BSA microspheres prepared using drug: polymer ratio of 1:5.

It is noticed that upon increasing the viscosity of the dispersion medium, there is a corresponding decrease in the particle size, (Fig. 4). The used dispersion media were isooctane, light paraffin oil, olive oil and linseed oil having viscosities of $0.5,66.2,75$ and 94 cp., respectively. Albumin microspheres having very large diameter were produced upon using isooctane as the dispersion medium $^{25 \& 26}$.

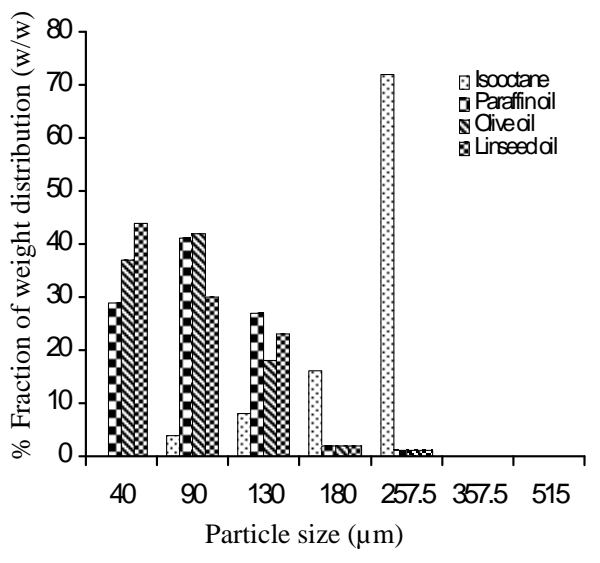

Fig. 4: Effect of different types of dispersion media on the $\%$ fraction of weight distribution of theophylline loaded BSA microspheres prepared using drug: polymer ratio of $1: 5$ and span 80 / tween 80 blend concentration of $1 \% \mathrm{w} / \mathrm{v}$.

The results reveal that upon increasing glutaraldehyde concentration from 5 to 10 and $25 \% \mathrm{v} / \mathrm{v}$, the amount of the produced microspheres having particle size less than $130 \mu \mathrm{m}$ were nearly of the same values, (Fig. 5). These data indicate that increasing glutaraldehyde concentration had no effect on the particle size range $^{24}$. 


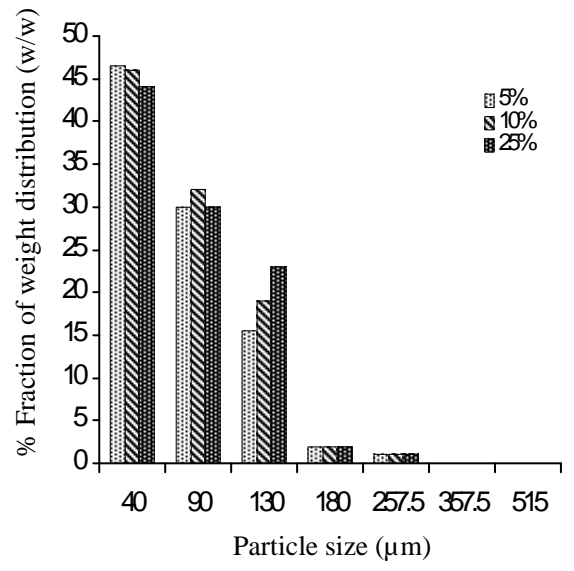

Fig. 5: Effect of different glutaraldehyde solution concentrations $(\% \mathrm{v} / \mathrm{v})$ on the $\%$ fraction of weight distribution of theophylline loaded BSA microspheres prepared using drug: polymer ratio of 1:5, span 80 / tween 80 blend concentration of $1 \% \mathrm{w} / \mathrm{v}$ and linseed oil as the dispersion medium.

\section{Encapsulation efficiency of theo- phylline}

It is obvious from (Fig. 6) that upon increasing albumin content in the aqueous phase during microspheres preparation, there is a remarkable increase in the loading efficiency till the drug: polymer ratio of 1:5 then the entrapment efficiency is decreased. The highest drug loading was found to be with the drug-albumin ratio of $1: 5$; so it was chosen and used in the next investigations. It is noticed from (Fig. 7) that increasing span 80 concentration from 0 to $1 \%$ increased the encapsulation efficiency from $33.7 \pm 8.11$ to $56.8 \pm 3.66 \%$. The encapsulation efficiency decreased to $38.9 \pm 7.05 \%$ for span 80 concentration $2 \% \mathrm{w} / \mathrm{v}$. The microspheres prepared using span 80 concentration of $1 \% \mathrm{w} / \mathrm{v}$ had the highest encapsulation efficiency so it was chosen and used in the next investigation.

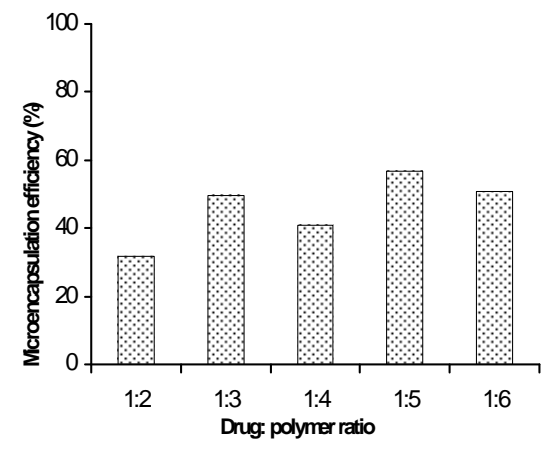

Fig. 6: Effect of different drug: polymer ratios on the encapsulation efficiency of theophylline loaded BSA microspheres.

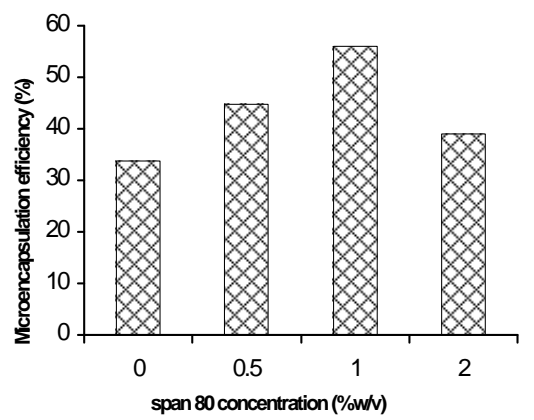

Fig. 7: Effect of different span 80 concentrations $(\% \mathrm{w} / \mathrm{v})$ on the encapsulation efficiency of theophylline loaded BSA microspheres prepared using drug: polymer ratio of 1:5. 
The microencapsulation efficiency of the microspheres prepared using span 80 / tween 80 blend is much more than those prepared with span 80 alone and ranged from $63.5 \pm 5.9$ to $85.3 \% \pm 4.5$, (Fig. 8 ). The microspheres prepared using blend concentration of $1 \% \mathrm{w} / \mathrm{v}$ has the highest encapsulation efficiency so it was chosen and used in the next investigation.

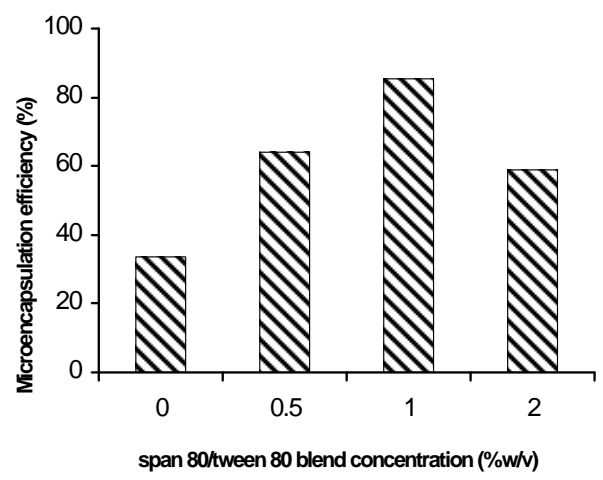

Fig. 8: Effect of different span 80 / tween 80 blend concentrations $(\% \mathrm{w} / \mathrm{v})$ on the encapsulation efficiency of theophylline loaded BSA microspheres prepared using drug: polymer ratio of $1: 5$.

The lower encapsulation efficiency $(74.64 \pm 2.4 \%)$ is noticed with the batch prepared with isooctane (low visciosity of $0.5 \mathrm{cp}$.) as a dispersion medium. The highest $(88.43 \% \pm 2.52) \quad$ encapsulation efficiency is noticed with batch prepared with linseed oil (high viscosity of $94 \mathrm{cp}$.) as the dispersion medium (so it was chosen and used in the next investigation) (Fig. 9). The batch prepared with glutaraldehyde concentration of $10 \% \mathrm{w} / \mathrm{v}$ has the highest encapsulation efficiency $(91.1 \% \pm 1.92)$ (Fig. 10). With the increase in the glutaraldehyde concentration from 5 to $10 \% \mathrm{w} / \mathrm{v}$, there was a slight increase in the encapsulation efficiency from $90 \pm$ 1.92 to $91.1 \% \pm 1.92$. The encapsulation efficiency was decreased from $91.1 \pm 1.92$ to $88.43 \%$ \pm 2.52 by increasing glutaraldehyde concentration from 10 to $25 \% \mathrm{v} / \mathrm{v}$.

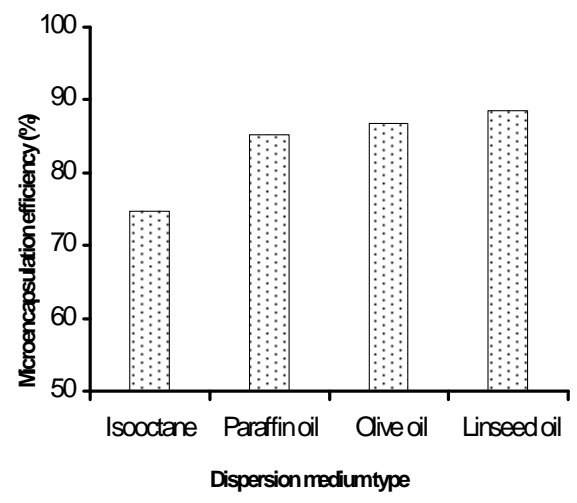

Fig. 9: Effect of different dispersion media on the encapsulation efficiency of theophylline loaded BSA microspheres prepared using drug: polymer ratio of 1:5 and span $80 /$ tween 80 blend concentration $1 \% \mathrm{w} / \mathrm{v}$. 


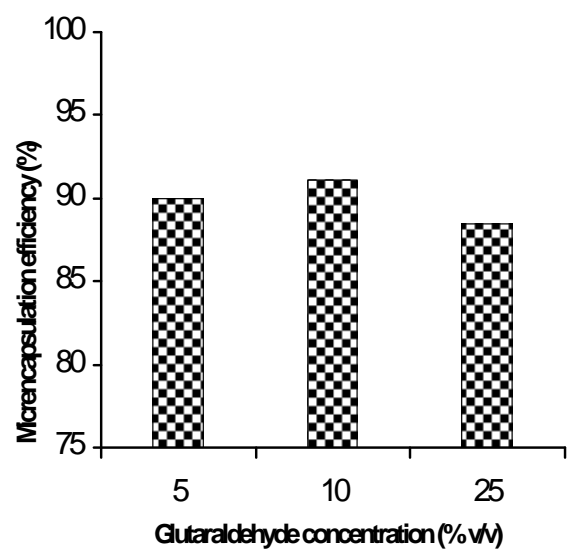

Fig. 10: Effect of different glutaraldehyde concentrations (\% $\mathrm{v} / \mathrm{v})$ on the encapsulation efficiency of theophylline loaded BSA microspheres prepared using drug: polymer ratio of $1: 5$, span $80 /$ tween 80 blend concentration $1 \% \mathrm{w} / \mathrm{v}$ and linseed oil as the dispersion medium.

\section{Theophylline in-vitro release study}

Generally drug release from microspheres as reviewed by Tomlinson $e t$ al. ${ }^{20}$ is characterized by an initial rapid release of the drug ("burst" release), followed by slower release of the remaining drug. The initial phase was completed within $2 \mathrm{hrs}$ and about $35-92 \%$ of the loaded theophylline was released during this period. Also the release rate was higher in SGF than SIF.

It is noticed from (Figs. 11\&12) that the theophylline release from the BSA microspheres was retarded with an increase in albumin content. Moreover, changing drug to polymer ratio from 1:2 to $1: 6$ decreased the amount of theophylline released from 79 to $40 \%$ after $2 \mathrm{hrs}$ of the experiment time course. In (Figs. $13 \& 14)$, when the BSA was used as a self-emulsifying agent (no Span 80 was added), the amount of theophylline released after $2 \mathrm{hrs}$ was $44.2 \%$ while this amount was increased to 53.4, 58.6 and $60.6 \%$ when span 80 was used at concentrations of $0.5,1$ and $2 \% \mathrm{w} / \mathrm{v}$, respectively after the same period.

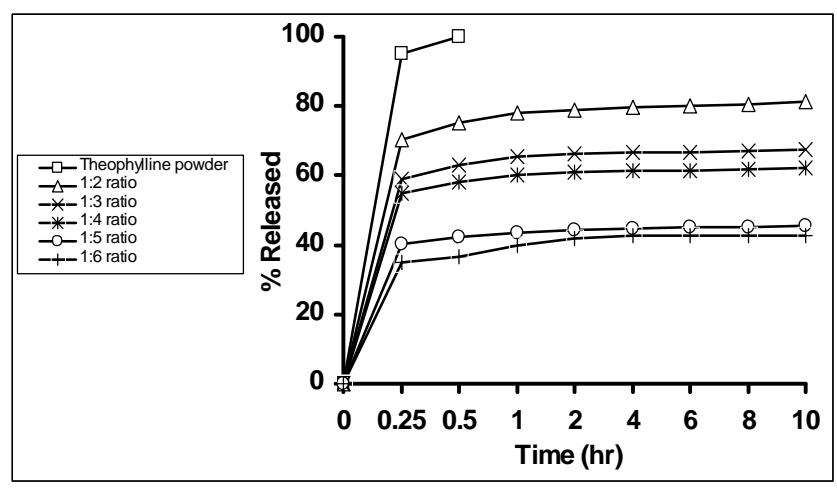

Fig. 11: Effect of different drug: polymer ratios on the in-vitro release of theophylline loaded BSA microspheres in SIF at $37^{\circ} \mathrm{C}$. 


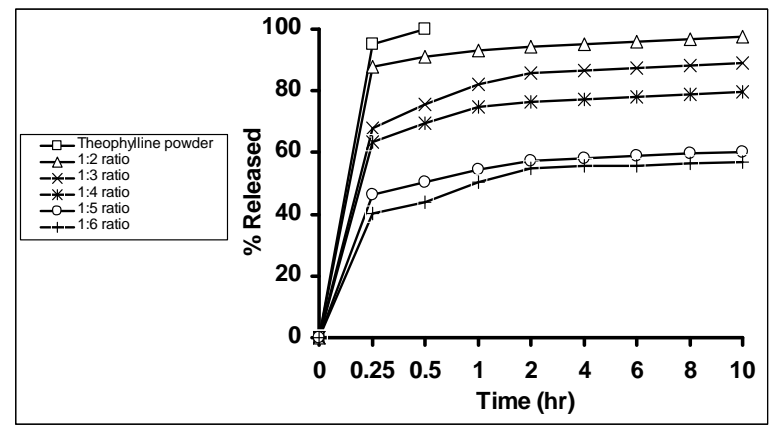

Fig. 12: Effect of different drug: polymer ratios on the in-vitro release of theophylline loaded BSA microspheres in SGF at $37^{\circ} \mathrm{C}$.

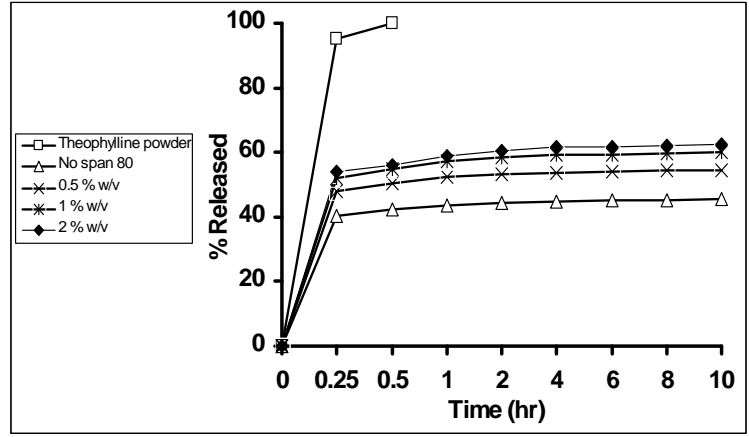

Fig. 13: Effect of different span 80 concentrations $(\% \mathrm{w} / \mathrm{v})$ on the in-vitro release of theophylline loaded BSA microspheres prepared using drug: polymer ratio of $1: 5$ in SIF at $37^{\circ} \mathrm{C}$.

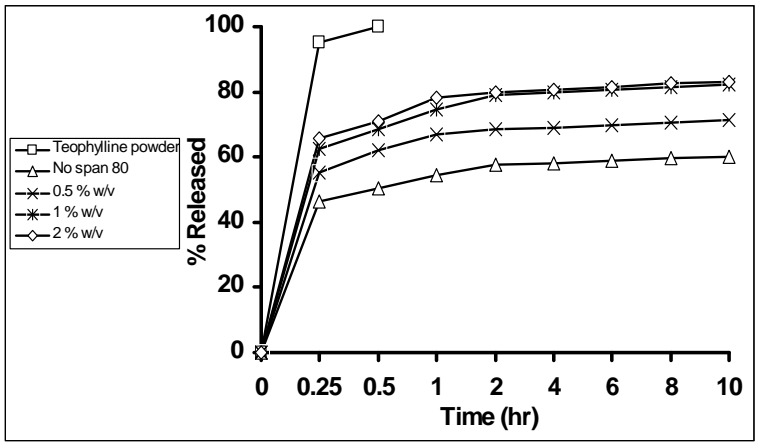

Fig. 14: Effect of different span 80 concentrations $(\% \mathrm{w} / \mathrm{v})$ on the in-vitro release of theophylline loaded BSA microspheres prepared using drug: polymer ratio of $1: 5$ in $\mathrm{SGF}$ at $37^{\circ} \mathrm{C}$. 
Theophylline release from the BSA microspheres prepared using span 80 / tween 80 blend as a surfactant was delayed somewhat and not greatly, (Figs. 15\&16). The amount of theophylline released after 2 hrs was $54 \%$, when span 80 / tween
80 blend was used at a concentration of $0.5 \%(\mathrm{w} / \mathrm{v})$. With increasing the amount of span $80 /$ tween 80 blend from 0.5 to 1 and $2 \%$, the amounts of theophylline released were 60 and $63.5 \%$, respectively.

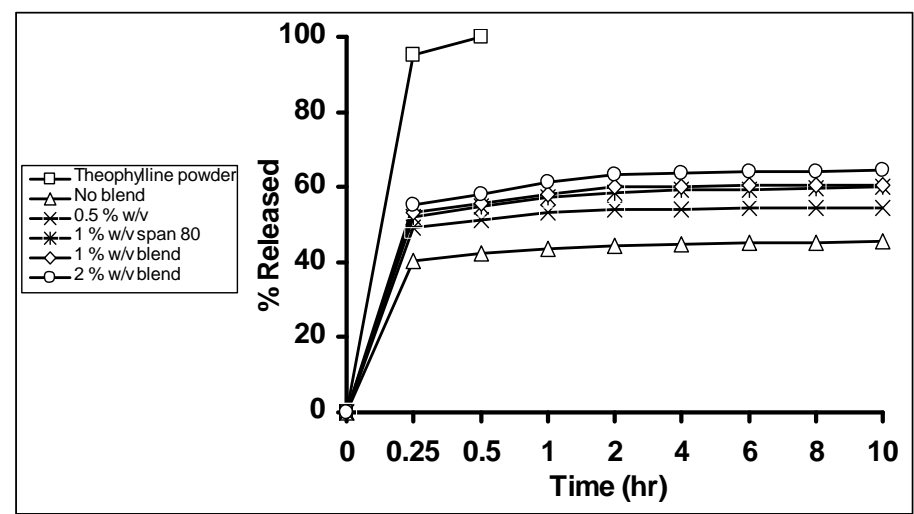

Fig. 15: Effect of different span 80 / tween 80 blend concentrations (\% w/v) on the invitro release of theophylline loaded BSA microspheres prepared using drug: polymer ratio of $1: 5$ in $\mathrm{SIF}$ at $37^{\circ} \mathrm{C}$.

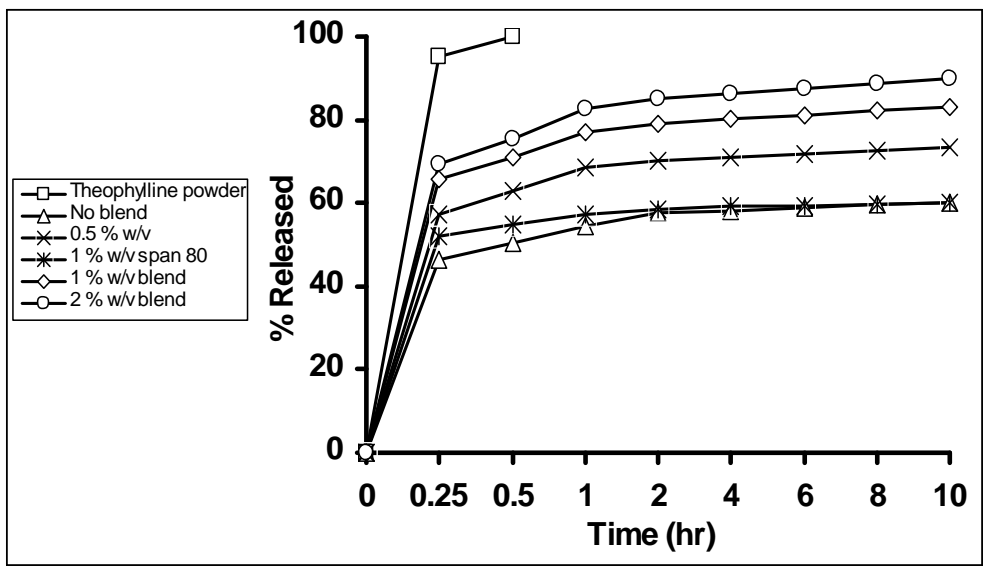

Fig. 16: Effect of different span 80 / tween 80 blend concentrations (\%w/v) on the invitro release of theophylline loaded BSA microspheres prepared using drug: polymer ratio of $1: 5$ in $\mathrm{SGF}$ at $37^{\circ} \mathrm{C}$. 
Theophylline release from the BSA microspheres was increased with an increase in the viscosity of the dispersion medium. When isooctane was used, the amount of theophylline released after 2 hrs was $49.5 \%$, while by increasing the viscosity using light paraffin oil, olive oil and linseed oil as dispersion media, the amounts of theophylline released were 60,65 and
$68 \%$ at the same selected period, respectively, (Figs. 17\&18). It is obvious from (Figs. 19\&20) that the release of theophylline was decreased with increasing glutaraldehyde concentration. With decreasing glutaraldehyde concentration from 25 to $5 \% \mathrm{v} / \mathrm{v}$, the amount of theophylline released after $2 \mathrm{hrs}$ increased from 68 to $85.46 \%$.

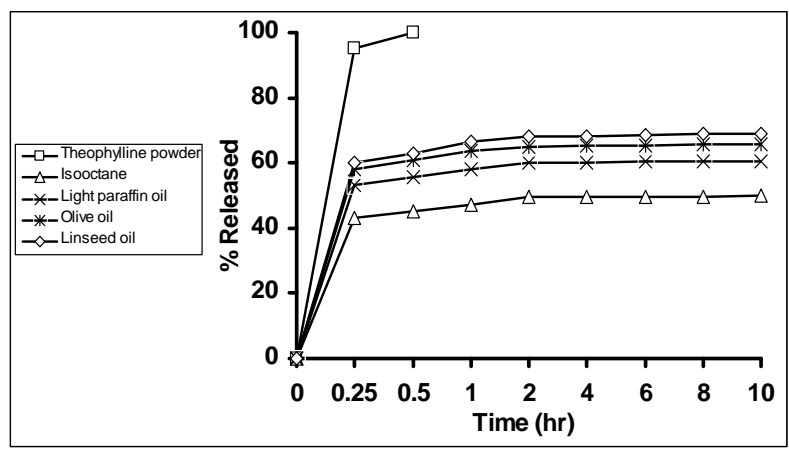

Fig. 17: Effect of different dispersion media on the in-vitro release of theophylline loaded BSA microspheres prepared using drug: polymer ratio of 1:5 and span $80 /$ tween 80 blend concentration of $1 \% \mathrm{w} / \mathrm{v}$ in SIF at $37^{\circ} \mathrm{C}$.

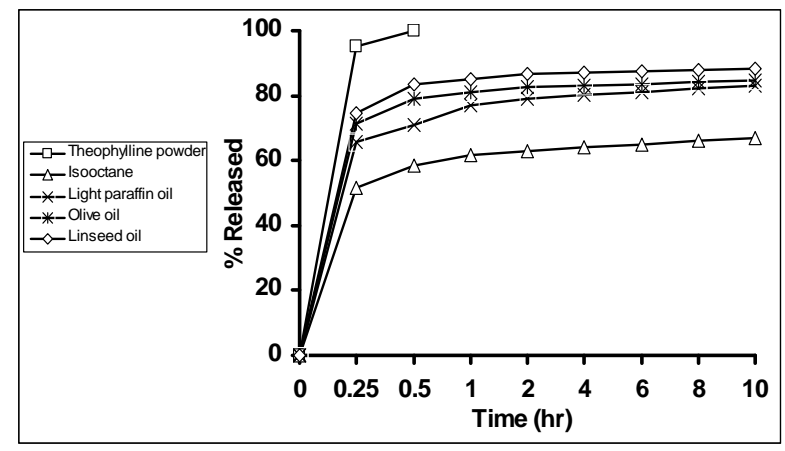

Fig. 18: Effect of different dispersion media on the in-vitro release of theophylline loaded BSA microspheres prepared using drug: polymer ratio of 1:5 and span $80 /$ tween 80 blend concentration of $1 \% \mathrm{w} / \mathrm{v}$ in SGF at $37^{\circ} \mathrm{C}$. 


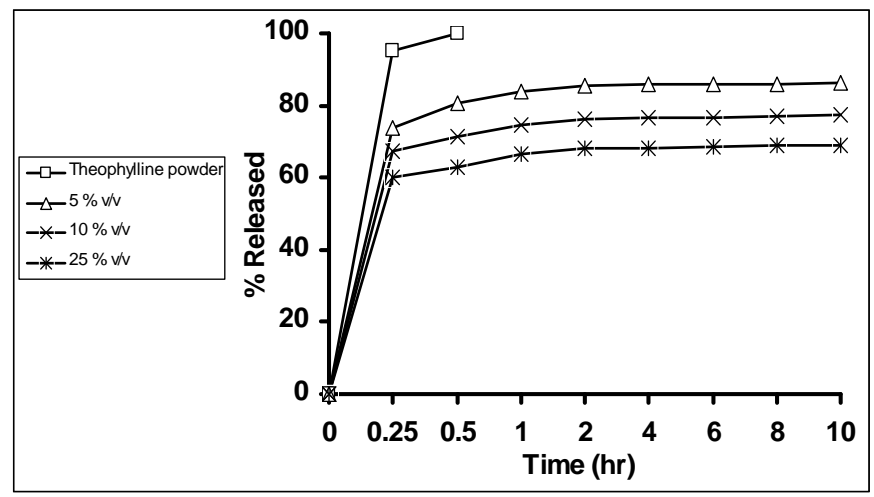

Fig. 19: Effect of different glutaraldehyde solution concentrations (\% v/v) on the invitro release of theophylline loaded BSA microspheres prepared using drug: polymer ratio of 1:5, span $80 /$ tween 80 blend concentration of $1 \% \mathrm{w} / \mathrm{v}$ and linseed oil as the dispersion medium in SIF at $37^{\circ} \mathrm{C}$.

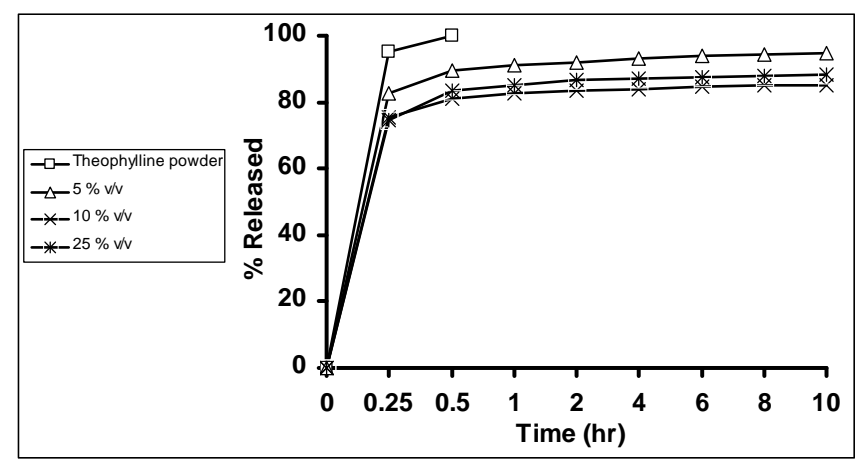

Fig. 20: Effect of different glutaraldehyde concentrations on the in-vitro release of theophylline loaded BSA microspheres prepared using drug: polymer ratio of 1:5, span 80 / tween 80 blend concentration of $1 \% \mathrm{w} / \mathrm{v}$ and linseed oil as the dispersion medium in SGF at $37^{\circ} \mathrm{C}$.

\section{Kinetics of the in-vitro drug release}

Tables (1-5) show that theophylline release from albumin microspheres was according to
Higuchi's diffusion model where it shows the highest correlation coefficient. 
Table 1: Kinetic data for in-vitro release of theophylline from albumin microspheres using different drug: polymer ratios in simulated intestinal fluid (SIF) at $37^{\circ} \mathrm{C}$.

\begin{tabular}{|c|c|c|c|}
\hline \multirow{2}{*}{$\begin{array}{l}\text { Drug: polymer } \\
\quad \text { ratio }\end{array}$} & \multicolumn{3}{|c|}{$\begin{array}{l}\text { The correlation coefficient (r) according to the } \\
\text { mechanisms of release }\end{array}$} \\
\hline & Zero order & First order & Higuchi's diffusion \\
\hline $1: 2$ & 0.723 & 0.774 & 0.816 \\
\hline $1: 3$ & 0.708 & 0.714 & 0.802 \\
\hline $1: 4$ & 0.729 & 0.747 & 0.826 \\
\hline $1: 5$ & 0.743 & 0.779 & 0.874 \\
\hline $1: 6$ & 0.724 & 0.749 & 0.847 \\
\hline
\end{tabular}

_- The underline indicates the mechanism of best fit.

Table 2: Kinetic data for in-vitro release of theophylline from albumin microspheres using a drug: polymer ratio of 1:5 at different span 80 concentrations in simulated intestinal fluid (SIF) at $37^{\circ} \mathrm{C}$.

\begin{tabular}{|c|c|c|c|}
\hline \multirow{2}{*}{$\begin{array}{c}\text { Span } 80 \\
\text { concentrations } \\
(\% \mathrm{w} / \mathrm{v}) \\
\end{array}$} & \multicolumn{3}{|c|}{$\begin{array}{l}\text { The correlation coefficient }(\mathrm{r}) \text { according to the } \\
\text { mechanisms of release }\end{array}$} \\
\hline & Zero order & First order & Higuchi's diffusion \\
\hline 0.5 & 0.726 & 0.735 & $\underline{0.858}$ \\
\hline 1 & 0.763 & 0.776 & $\underline{0.857}$ \\
\hline 2 & 0.767 & 0.798 & 0.896 \\
\hline
\end{tabular}

__ The underline indicates the mechanism of best fit.

Table 3: Kinetic data for in-vitro release of theophylline from albumin microspheres using a drug: polymer ratio of 1:5 at different span 80 / tween 80 blend concentrations in simulated intestinal fluid (SIF) at $37^{\circ} \mathrm{C}$.

\begin{tabular}{|c|c|c|c||}
\hline $\begin{array}{c}\text { Span 80/ tween 80 } \\
\text { blend concentrations } \\
(\% \mathrm{w} / \mathrm{v})\end{array}$ & \multicolumn{3}{|c|}{ The correlation coefficient (r) according to the } \\
mechanisms of release
\end{tabular}

__ The underline indicates the mechanism of best fit. 
Table 4: Kinetic data for in-vitro release of theophylline from albumin microspheres using a drug: polymer ratio of 1:5 and span 80 / tween 80 blend concentration of $1 \% \mathrm{w} / \mathrm{v}$ in different types of dispersion media in simulated intestinal fluid (SIF) at $37^{\circ} \mathrm{C}$.

\begin{tabular}{|c|c|c|c||}
\hline \multirow{2}{*}{$\begin{array}{c}\text { Dispersion } \\
\text { medium }\end{array}$} & \multicolumn{3}{|c|}{ The correlation coefficient (r) according to the } \\
& \multicolumn{3}{|c||}{ mechanisms of release } \\
\cline { 2 - 4 } & Zero order & First order & Higuchi's diffusion \\
\hline Isooctane & 0.696 & 0.719 & $\underline{0.842}$ \\
\hline Light paraffin oil & 0.744 & 0.769 & $\underline{0.845}$ \\
\hline Olive oil & 0.725 & 0.727 & $\underline{0.825}$ \\
\hline Linseed oil & 0.678 & 0.731 & $\underline{0.792}$ \\
\hline
\end{tabular}

__ The underline indicates the mechanism of best fit.

Table 5: Kinetic data for in-vitro release of theophylline from albumin microspheres using a drug: polymer ratio of $1: 5$, span $80 /$ tween 80 blend concentration of $1 \% \mathrm{w} / \mathrm{v}$ and linseed oil as the dispersion medium at different glutaraldehyde solution concentrations $(\% \mathrm{v} / \mathrm{v})$ in simulated intestinal fluid (SIF) at $37^{\circ} \mathrm{C}$.

\begin{tabular}{|c|c|c|c||}
\hline \multirow{2}{*}{$\begin{array}{c}\text { Glutaraldehyde } \\
\text { solution } \\
\text { concentrations } \\
(\% \mathrm{v} / \mathrm{v})\end{array}$} & \multicolumn{3}{|c||}{$\begin{array}{c}\text { The correlation coefficient (r) according to the } \\
\text { mechanisms of release }\end{array}$} \\
\cline { 2 - 4 } & Zero order & First order & Higuchi's diffusion \\
\hline 5 & 0.724 & 0.738 & $\underline{0.824}$ \\
\hline 10 & 0.724 & 0.725 & $\underline{0.824}$ \\
\hline 25 & 0.678 & 0.731 & $\underline{0.792}$ \\
\hline
\end{tabular}

__ The underline indicates the mechanism of best fit. 


\section{Bioavalability}

The obtained data are graphically illustrated in (Fig. 21). The pharmaco- kinetic parameters are represented in (Table 6).

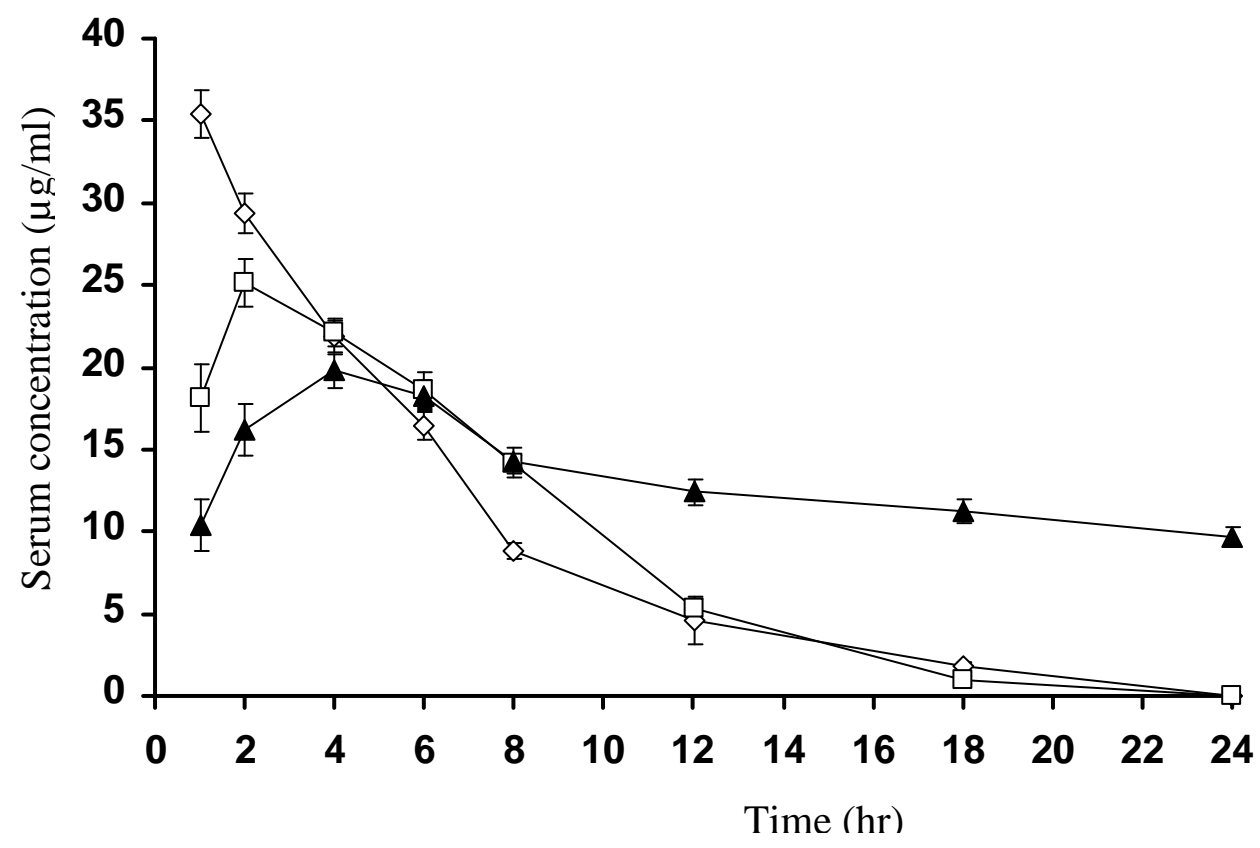

$\neg$ Intravenous $\neg \square$ Theophylline powder $\neg \multimap$ Theoeophylline loaded albumin microspheres

Fig. 21: Serum theophylline concentration $(\mu \mathrm{g} / \mathrm{ml})$ after intravenous injection and oral administration of theophylline powder and theophylline loaded BSA microspheres to rabbit. 
Table 6: Pharmacokinetic parameters for in-vivo study of theophylline after intravenous injection and oral administration of theophylline loaded BSA microspheres and powder.

\begin{tabular}{|c|c|c|c|}
\hline \multirow{3}{*}{ Parameter } & \multicolumn{3}{|c|}{ Administered form } \\
\hline & \multirow{2}{*}{$\begin{array}{c}\text { Intravenous } \\
\text { injection }\end{array}$} & \multicolumn{2}{|c|}{ Oral } \\
\hline & & Powder & BSA microspheres \\
\hline $\mathrm{C} \max (\mu \mathrm{g} / \mathrm{ml})$ & 35.1 & 25.11 & 19.78 \\
\hline $\mathrm{C} \min (\mu \mathrm{g} / \mathrm{ml})$ & 0.05 & 0.97 & 9.7 \\
\hline $\mathrm{t} \max (\mathrm{hr})$ & 1 & 2 & 4 \\
\hline $\mathrm{K}$ abs $(\mathrm{hr})^{-1}$ & - & 0.363 & 1.797 \\
\hline $\mathrm{t}_{1 / 2}$ abs $(\mathrm{hr})$ & - & 1.908 & 0.385 \\
\hline $\mathrm{K} \mathrm{el} \mathrm{(hr})^{-1}$ & 0.201 & 0.230 & 0.030 \\
\hline $\mathrm{t}_{1 / 2} \mathrm{el}(\mathrm{hr})$ & 3.013 & 3.440 & 22.61 \\
\hline $\mathrm{MRT}^{*}(\mathrm{hr})$ & 5.037 & 5.921 & 17.55 \\
\hline $\begin{array}{l}\text { Volume of distribution } \\
(\mathrm{L})\end{array}$ & 0.648 & 1.145 & 1.565 \\
\hline $\begin{array}{l}\text { Total clearance rate } \\
(\mathrm{ml} / \mathrm{min})\end{array}$ & 2.177 & 4.391 & 0.799 \\
\hline $\mathrm{AUC}_{0-24}(\mu \mathrm{g} . \mathrm{hr} / \mathrm{ml})$ & 184.6 & 211.84 & 311.65 \\
\hline $\mathrm{AUC}_{24-\infty}(\mu \mathrm{g} . \mathrm{hr} / \mathrm{ml})$ & 0 & 0 & 316.52 \\
\hline $\mathrm{AUC}_{0-\infty}(\mu \mathrm{g} . \mathrm{hr} / \mathrm{ml})$ & 184.6 & 211.84 & 628.18 \\
\hline $\begin{array}{c}\text { Peak-to-trough } \\
\text { difference }^{* *}(\mu \mathrm{g} / \mathrm{ml})\end{array}$ & 35.05 & 24.14 & 10.08 \\
\hline $\begin{array}{c}\text { Relative } \\
\text { bioavailability }^{* * *} \% \\
\end{array}$ & - & - & 147.11 \\
\hline $\begin{array}{c}\text { Absolute } \\
\text { bioavailability }^{* * * *} \%\end{array}$ & - & - & 168.82 \\
\hline $\operatorname{AUMC}_{0-24}\left(\mu \mathrm{g} \cdot \mathrm{hr}^{2} / \mathrm{ml}\right)$ & 929.95 & 1254.45 & 3429.46 \\
\hline $\mathrm{AUMC}_{24-\infty}\left(\mu \mathrm{g} \cdot \mathrm{hr}^{2} / \mathrm{ml}\right)$ & 0 & 0 & 7596.69 \\
\hline $\mathrm{AUMC}_{0-\infty}\left(\mu \mathrm{g} \cdot \mathrm{hr}^{2} / \mathrm{ml}\right)$ & 929.95 & 1254.45 & 11026.16 \\
\hline $\mathrm{C} \max / \mathrm{AUC}_{0-24}(\mathrm{hr})^{-1}$ & 0.190 & 0.118 & 0.063 \\
\hline
\end{tabular}

$-=$ Not relevant.

$\mathrm{MRT}^{*}=$ Mean residence time.

Peak-to-trough difference ${ }^{* *}=\mathrm{C} \max -\mathrm{C}$ min.

Relative bioavailability ${ }^{* * *}=\left(\mathrm{AUC}_{0-24}\right.$ for oral formula/ $/ \mathrm{AUC}_{0-24}$ for powder $) \times 100$.

Absolute bioavailability ${ }^{* * * *}=\left(\mathrm{AUC}_{0-24}\right.$ for oral formula/AUC $\mathrm{AU}_{0-24}$ for intravenous $)$ $\times 100$. 


\section{Conclusion}

Increasing the polymer content of the aqueous phase, span 80 concentration and viscosity of the dispersion medium decreased the size of the prepared microspheres. It was found that increasing glutaraldehyde concentration has no effect on the particle size range. Encapsulation efficiency is increased by increasing albumin content, surfactant concentration, viscosity of the dispersion medium and glutaraldehyde concentration. Drug release from microspheres is characterized by an initial rapid release of the drug ("burst" release), followed by slower release of the remaining drug. The controlled release formulae of theophylline BSA microspheres show good in-vitro controlled release characteristics, continued to exhibit a good in-vivo controlled release behavior. They show good relative bioavailability, a longer duration of action, a small peak-to-trough difference and a lower fluctuation compared to the intravenous theophylline or theophylline powder.

\section{REFERENCES}

1- J. J. Burger, E. Tomlinson, E. M. A. Mulder and J. G. McVie, Int. J. Pharm., 23, 333 (1985).

2- Y. Nishioka, S. Kyotani, M. Okamura, Y. Mori, M. Miyazaki, K. Okazaki, S. Ohnishi, Y. Yamamoto and K. Ito, Chem. Pharm. Bull., 37, 1399 (1989).

3- S. P. Vays, S. Bhatnagar, P. J. Gogol and N. K. Jain, Int. J. Pharm., 69, 5 (1991).
4- P. K. Gupta, C. T. Hung and D. G Perrier, ibid., 33, 147 (1986).

5- P.K. Gupta, C.T. Hung, F.C. Lam and D.G Perrier, ibid., 43, 167 (1988)

6- K. Egbaria and M. Frieddman, J. Control. Rel., 14, 79 (1990).

7- K. Sugibayashi, Y. Morimoto, T. Nadai, Y. Kato, A. Hasegawa and T. Arita, Chem. Pharm. Bull., 27, 204 (1979).

8- C. Jones, M. A. Burton and B. N. Gray, J. Pharm. Pharmacol., 41, 813 (1987).

9- I. Zoll, B. A. Rhodes and H. N. Wagner, Int. J. Appl. Radiat. Isot., 21, 155 (1970).

10- P. A. Kramer, J. Pharm. Sci., 63, 1646 (1974).

11- K. J. Widder, G. Flouret and A. Senyei, ibid., 68, 79 (1979).

12- B. Farhadieh, US Patent, 3, 922, 379 (1975)

13- T. K. Lee, T. D. Sokoloski and G. P. Royer, Science, 213, 233 (1981).

14- J. J. Burger, E. Tomlinson, E. M. A. Mulder and J. G. McVie, in: P. Buri and A. Gumma (Eds.), "Drug Targeting", Elsevier, Amsterdam, 1985, pp. 81-94.

15- A. E. Senyei, S. D. Reich, C. Gonczy and K. J. Widder, J. Pharm. Sci., 70, 389 (1981).

16- T. Kojima, M. Hashida, S. Muranishi and H. Sezaki, Chem Pharm. Bull., 26, 1818 (1978).

17- M. El-Samaligy and P. Rohdewald, Pharm. Acta Helv., 57, 201 (1982). 
18- A. F. Yapel, US Patent, 4, 147, 767 (1979).

19- H. Sezaki, M. Hashida and S. Muranishi, in: H. Bund-Gaard, A.B. Hansen and H. Koford (Eds.), "Optimization of Drug Delivery", Munksgard, Copenhagen, 1982, pp. 316-339.

20- B. Tomlinson, J. J. Burger, E. M. A. Schoonder-Woerd, J. Kuik, F. C. Scholtz and J. G. McVie, "Human Serum Albumin Microspheres For Intraarterial Drug Targeting of Cytostatic Compounds. Pharmaceutical Aspects and Release Characteristics". In S.S. Davis, L. IIIum, J.G. McVie and E. Tomlinson (Eds.), "Microspheres and Drug Therapy", Elsevier, Amesterdam, 1984, pp.75-89.
21- M. J. Stoklosa and H. C. Ansel, in: "HLB System: Problems Involving HLB Values, Pharmaceutical Calculations", Middle East Ed., Mass Publishing Co., Egypt, 1997, pp 129-139.

22- M. S. Latha, K. Rathinam, P. V. Mohanan and A. Jayakrishnan, J. Control. Rel., 34, 1 (1995).

23- K. Maruyama, Y. Pongpaibul and M. Iwatsuru, ibid, 10, 17 (1989).

24- Wen-Ho Chuo, Tong-Rong Tsai, Shu-Hui Hsu and Thau-Ming Cham, Int. J. Pharm., 144, 241 (1996).

25- W. I. Higuchi, R. Okada and A. P. Lemberger, J. Pharm. Sci., 51, 683 (1962).

26- G. Q. Chen, W. Lin, A. G. A Coombes, S. S. Davis and L. Illum, J. Microencap., 11, 395 (1991). 